\title{
Genetics of aniridia and anterior segment dysgenesis
}

\author{
Amanda Churchill, Adam Booth
}

\section{Embryology of the anterior segment}

During embryogenesis neural crest cells differentiate to form a large portion of the anterior segment of the eye. There is a structured sequence to these events whereby crest cells and mesoderm (collectively known as secondary mesenchyme) migrate into the developing eye in three waves after the basement membrane of the surface ectoderm and the lens vesicle separate. The first wave of crest cells differentiates to form the trabecular meshwork and corneal endothelium (which secretes Descemet's membrane). The second wave gives rise to the corneal keratocytes, and the cells of the third wave contribute to the development of the iris $^{1}$ (Fig 1).

\section{A link between anterior segment dysgenesis, aniridia, and neural crest cells}

Anterior segment mesenchymal dysgenesis has replaced the original classification of anterior segment cleavage syndrome. ${ }^{2}$ It is thought to be more accurate because embryologically there is no development of a cleavage plane as the anterior segment forms and differentiates. There are a number of eponymous conditions that arise because of anterior segment mesenchymal dysgenesis-Axenfeld's, Peters' and Rieger's anomalies-although there is considerable overlap in the clinical features (Fig 2).

The hallmark of Peters' anomaly is a congenital corneal opacity with underlying defects in the posterior stroma, Descemet's membrane, and endothelium. Iris synechiae from the collarette to the periphery of the corneal opacity are frequently present as are keratolenticular strands. ${ }^{3}$ Fifty per cent of patients with Peters' anomaly develop early onset glaucoma.

Congenital hereditary endothelial dystrophy (CHED) is due to a severe dystrophy or absence of endothelium causing diffuse bilateral corneal oedema that may progress to a ground glass appearance. Since corneal endothelium is a neural crest derived tissue, some authors believe it should be included among the anterior segment dysgenesis syndromes. ${ }^{4}$

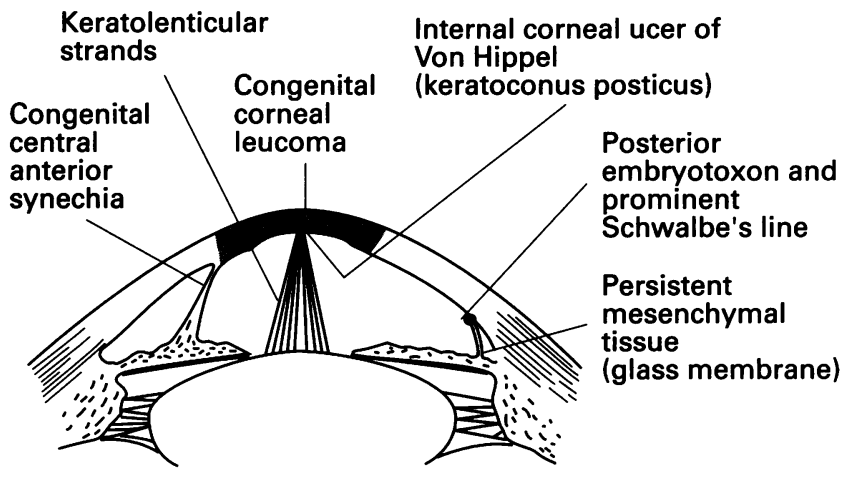

Figure 2 Features of anterior segment dysgenesis. (Modified from Reese and Ellsworth ${ }^{50}$.)

Sclerocornea is a scleralisation and vascularisation of the anterior surface of the globe, associated with corneal flattening (cornea plana) and loss of limbal landmarks. The condition is variable in severity, frequently bilateral, and always non-progressive. Anterior chamber angle anomalies are commonly associated. ${ }^{5}$

These three conditions have been attributed to abnormalities arising from faulty migration or function of the first wave of neural crest cells. ${ }^{167}$

Axenfeld described anterior displacement and prominence of Schwalbe's line (posterior embryotoxon) with attached strands of iris. The presence, in addition, of severe iris atrophy and corectopia is called Rieger's anomaly. Fifty per cent of patients with Rieger's anomaly develop glaucoma; they have a similar age of onset as that seen in Peters' anomaly. Corneal leucomas may occur peripherally in either condition. Rieger's syndrome is the name given when these ocular features are found in association with other defects such as facial, dental, or skeletal abnormalities, and failure of involution of the umbilicus. These conditions are thought to arise when there is faulty migration of the third wave of neural crest cell migration. ${ }^{1}$

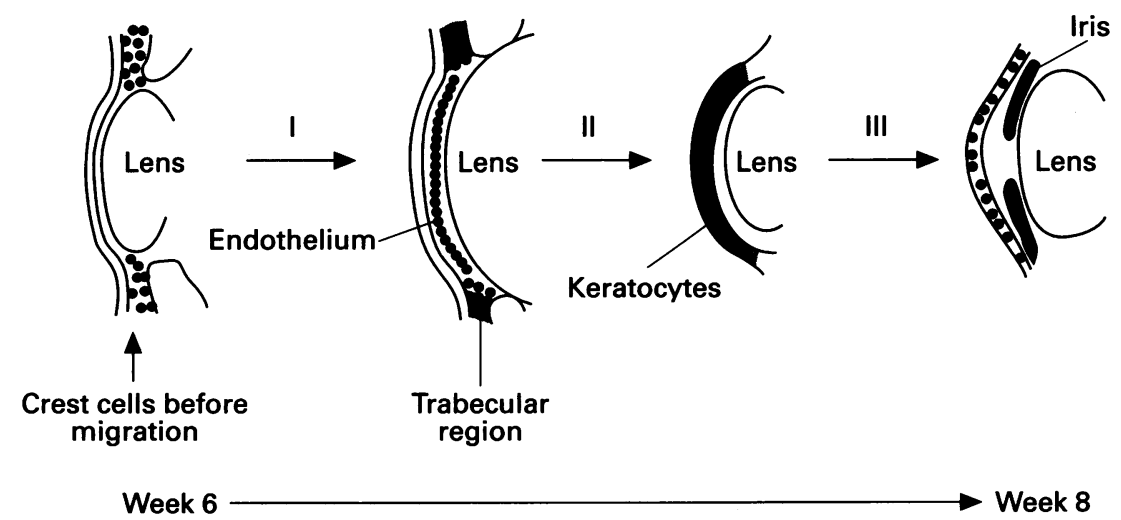

Figure 1 The three waves of neural crest cell migration during embryogenesis. Wave I, trabecular meshwork and endothelium; wave II, corneal stroma and keratocytes; wave III, iris. (Modified from Bahn et al ${ }^{t}$.) 
Categorising a patient as having one particular anomaly can be difficult as considerable overlap exists between them. Salmon et al described a family of 39 members who had autosomal dominant microcornea and cataract. An additional six family members had sclerocornea or Peters' anomaly. Several members exhibited a posterior embryotoxon with or without microcornea. ${ }^{6}$ Tulloh $^{8}$ and Howard ${ }^{9}$ have described posterior embryotoxon, Axenfeld's and Rieger's anomalies in association with sclerocornea.

Aniridia is a condition characterised by partial or complete absence of iris tissue. It is frequently associated with corneal pannus, nystagmus, poor vision, cataracts, foveal hypoplasia, and glaucoma. Aniridia can be either sporadic or familial in origin. The mode of inheritance is usually autosomal dominant but an autosomal recessive transmission has been observed in the rare Gillespie syndrome in which aniridia is associated with cerebellar ataxia and mental retardation. ${ }^{10}$

In the past 3 years it has been demonstrated that rat 'Small eye' (a condition phenotypically similar to human aniridia) is associated with impaired migration of midbrain neural crest cells. ${ }^{11}$ Thus, aniridia and the anterior segment dysgenesis syndromes can be grouped together as being due to a defect in the control of neural crest cell migration into the developing eye.

\section{The genetics of aniridia}

It was originally thought that there were two human aniridia genes, one on chromosome 2 responsible for the inherited type (AN1), and one on chromosome 11 responsible for the sporadic type (AN2). It has subsequently been shown that the chromosome 2 locus is not involved in aniridia.

Chromosome 11 focused attention because it was known that a number of sporadic aniridia cases also develop Wilms' tumour, genitourinary abnormalities, and mental retardation (WAGR syndrome). The Wilms' tumour gene had already been located on the short arm of chromosome 11 (the short arm of any chromosome is given the symbol ' $p$ ') adjacent to genes involved in the development of the genitourinary and central nervous system. Karyotype analysis of patients with these developmental abnormalities revealed that the WAGR syndrome occurred when there was a deletion of chromosome $11 \mathrm{p}$ encompassing a number of genes. From this observation it followed that the aniridia gene should be located in the approximate vicinity of the Wilms' tumour gene. The aniridia gene (AN2) has been extensively studied in the past 6 years and the location confirmed as band 13 on chromosome $11 \mathrm{p}^{12}$

Jotterand et al described three cases of Wilms' tumour and sporadic aniridia, all having a deletion of the short arm of chromosome 11. One case, however, showed an iridocorneal adherence with an overlying corneal opacity reminiscent of Peters' anomaly. Interestingly, this patient also showed mosaicism with $68 \%$ normal cells and $32 \%$ exhibiting the aniridia deletion. ${ }^{13}$ This is another illustration of the overlap between aniridia and the anterior segment dysgeneses. Other workers have described patients with abnormalities in chromosome $11 \mathrm{p} 13$ who have dominantly inherited aniridia with no Wilms' tumour association. ${ }^{14}$ These deletions were observed by cytogenetic analysis of chromosomes from affected individuals but gave no specific information as to the exact location of the aniridia gene.

Most of the early work on the genetics of aniridia came from animal studies, particularly in the mouse. Small eye $(S e y)$ is a semidominant mutation in mice which in the homozygous condition results in a complete lack of eyes and nasal cavities with death soon after birth. In the heterozygous state, however, the eyes are present but underdeveloped. The gene responsible for Sey is on mouse chromosome 2 in a region syntenic with human chromosome $11 \mathrm{p} 13 .^{1516}$ On the basis of these comparative mapping studies and the phenotypic similarities Sey is considered to be homologous to human aniridia. ${ }^{17} 18$

Having an animal model with a known gene responsible for the condition allowed the study of aniridia to proceed rapidly. The Small eye gene was found to contain a region of DNA that is conserved in many different vertebrate and invertebrate species through evolution. This sequence was first identified in the fruit fly, Drosophila melanogaster, in a segmentation gene called paired. Molecular biologists traditionally highlight conserved sequence domains by literally drawing a box around them so this region of conserved DNA became known as the 'paired box' (Pax). Mammalian genes containing this region are known as ' $P a x$ ' genes (the use of capital letters distinguishes human from mouse Pax genes and italics denote the gene as opposed to the protein). The Pax gene family have been the focus of much attention in recent years because the paired box encodes a protein domain with DNA binding ability. ${ }^{1920}$ This has led to the concept of Pax genes functioning as major controllers in development by switching on and off expression of other genes. Nine Pax genes have been identified and are designated as Pax 1-9. ${ }^{21}$ The Small eye gene is called Pax 6. Further investigation of Pax 6 revealed a second DNA binding domain which was called the homeobox (Hox). Pax 3, 4, 6, and 7 proteins contain both paired and homeobox domains which allows very specific binding to other, as yet unknown, regions of the genome. This binding may directly stimulate expression of other genes if the protein attaches to a promoter site. Alternatively, it may inhibit expression by blocking the binding of other regulatory proteins or transcription factors to these promoter sites. Vertebrate genes containing the homeobox region alone are known as Hox genes and have been designated $H o x A-D$. Beebe has reviewed the Hox genes involved in eye development. ${ }^{22}$

The Small eye gene was used as a probe in two different experiments both of which relied on the ability of the probe to hybridise (bind) to a region of complementary human DNA. In the first experiment a solution containing the fluorescent gene probe was hybridised to a spread of normal human chromosomes. The probe bound to an area on the short arm of chromosome 11 which had already been observed to be deleted by cytogenetic analysis of patients with aniridia. This confirmed the probable approximate position of the aniridia gene.

The second experiment was designed to see whether the human fetal eye contained messenger RNA (mRNA) that was sufficiently similar to the mouse gene probe for hybridisation to occur. If positive this would indicate that there was a gene (similar to that in the mouse) that was actively being expressed in the fetal eye. As mRNA is notoriously unstable and degrades too rapidly for use in experiments a stable alternative was needed. By using a process known as reverse transcription a stable copy DNA (cDNA) was made from the original mRNA. Libraries containing cDNA can be made from whole organs and stored almost indefinitely for research purposes. Thus, in the second experiment, a cDNA library was made from human fetal eye mRNA and probed with the mouse Small eye gene. The positive hybridisation allowed a human CDNA to be identified that closely resembled the mouse gene. In an epic piece of work Ton et al identified and sequenced this candidate aniridia gene cDNA and showed this to be homologous to mouse Small eye (Pax 6). ${ }^{12}$

Having identified a potential candidate 'aniridia mRNA' in the human fetal eye it was then necessary to show that 
mutations were present in affected individuals. No detail about the gene itself was known at this stage-for example, how many introns and exons were present, so analysis was confined to the mRNA (or cDNA) level. Finding readily accessible tissue for analysis proved to be the first hurdle because although PAX 6 mRNA is found in adult brain it is not present in the peripheral blood. The way around this is to create lymphoblastoid cell lines from aniridia patients and isolate the illegitimate $P A X 6 \mathrm{mRNA}$ transcripts that are produced after this process. Once the mRNA sequence is known the amino acids and protein structure can be predicted.

Study of the human PAX 6 protein revealed that some amino acids are grouped together in such a way that the protein is twisted into a number of helical structures. The configuration of these helices appears to be vital for normal protein function. The paired domain starts near the first methionine residue at the amino $(\mathbf{N})$ terminal and contains three helices, the second and third of which are arranged in a helix-turn-helix configuration. The $\mathrm{N}$ terminal half of the paired domain, including the first helix, appears to determine the specificity of DNA to which the PAX 6 protein binds. ${ }^{23}$ The homeodomain also contains three helices: the third helix contacts the major groove of the DNA and is responsible for sequence recognition. ${ }^{24}$ The carboxy (C) terminal segment of the protein is rich in the amino acids proline, serine, and threonine (PST). This is a feature of the activation domains of some transcription factors-for example, CTF-1 and Oct-2, which may indicate a similar role for the PAX 6 protein (Fig 3). ${ }^{25}$ Interestingly, the gene products (proteins) from mouse and human $P A X 6$ were shown to be identical apart from one amino acid in the alternatively spliced form of the human protein. ${ }^{27} 28$

Using reverse transcription and nested polymerase chain reaction (PCR) techniques it has been shown that mutations in Pax 6 are associated with the Sey phenotype in mouse and rat and with aniridia in humans. ${ }^{12}{ }^{29}$ Many of the aniridia mutations are nonsense point mutations causing premature termination of protein translation and hence a foreshortened product. The affected individuals are, however, heterozygotes and always have one normal copy of Pax 6. A human homozygote was reported in 1980 by Hodgson and Saunders as being born with no eyes and no nose mimicking the Sey homozygote in the mouse. ${ }^{30}$

It was not until the genomic organisation detailing the intron-exon boundaries was published that PCR amplification mutation detection systems could be used to examine mutations at the DNA level. The gene was shown to be approximately 22 kilobases $(\mathrm{kb})$ in size, containing 14 exons (one being alternatively spliced) and the regions specifying the paired and homeodomains were identified. The DNA sequence of each exon and the intron-exon boundaries are known but the rest of the intervening (intronic) sequences, including the $5^{\prime}$ (regulatory) and $3^{\prime}$ untranslated regions are still not available from computer databases.

There are a large number of mutations causing aniridia recorded in the literature, examples of which are shown in

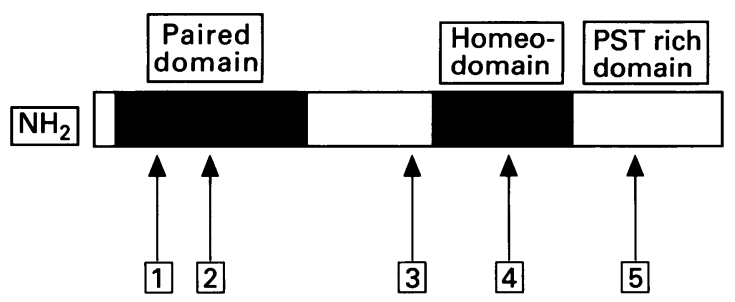

$\mathrm{COOH}$

Figure 3 The PAX 6 protein domains and some examples of known aniridia mutations. Mutation references: 1 and 2 (Martha et al ${ }^{51}, 3$ (Hanson et al ${ }^{52}$ ), 4 (Martha et al ${ }^{53}$ ), 5 (fordan et al ${ }^{29}$ ).
Figure 3. Clearly these are not confined to one particular region of the gene and the severity of the phenotype does not correlate with the type or position of the deletion/ mutation. It therefore seems most likely that aniridia results from the loss of one active copy of $P A X 6$ resulting in a reduced gene dosage and less protein product (haploinsufficiency). How exactly this affects the developing eye is still not known but there are an increasing number of syndromes thought to occur as a result of haploinsufficiency; Waardenburg, Williams, Goltz, and Dandy-Walker syndromes being just a few examples. ${ }^{31}$ It is not fully understood why some aniridia patients have no detectable mutations in the $P A X 6$ gene and conversely why mutations outside the $P A X 6$ region give rise to aniridia. It has been suggested that the former situation may arise if one copy of the PAX 6 gene has been completely deleted (thereby giving rise to less PAX 6 protein) or if the mutation is in an area upstream of the gene that controls the level of expression of $P A X 6$ (a regulatory area). It has also been postulated that patients who phenotypically exhibit aniridia but have a normal $P A X 6$ may have mutations in a second aniridia gene or it may be that by altering the local chromatin environment normal gene expression is inhibited. This is illustrated by three individuals with aniridia who have no detectable mutations in their $P A X 6$ genes but chromosomal translocation breakpoints which disrupt the DNA downstream of $P A X 6^{32}$

Glaser studied three families with the rare Gillespie syndrome (aniridia, cerebellar ataxia, and mental retardation) but found no mutations in $P A X 66^{33}$

\section{Expression pattern of $P A X 6$}

In order to try and understand how $P A X 6$ affects the developing eye one must look at where and when it is expressed in the embryo. Using mRNA in situ hybridisation techniques it has been shown that Pax 6 is expressed in the developing eye, nose, forebrain, and neural tube in the mouse. ${ }^{34}$ It is interesting that mutations in $P A X 6$ do not cause more widespread phenotypic abnormalities. Perhaps there is overlap in the function of the $P A X$ gene family and deficiencies of one can be compensated to some extent by increased expression of another.

Abitbol et al recently published the results of detailed studies of $P A X 6$ expression in human embryos between 3 and 6 weeks after fertilisation. ${ }^{35} P A X 6 \mathrm{mRNA}$ is initially found throughout the entire neural tube confirming its role in neurogenesis. Later it is found in the di- and telencephalon, in part of the rhombencephalon and spinal cord. Interestingly it is not expressed in the developing cerebellum although $P A X 6 \mathrm{mRNA}$ transcripts can be isolated from adult cerebellar cortex. In the eye, $P A X 6$ is expressed in the surface ectoderm (destined to become the lens and cornea) and in the inner and outer (but not the intermediate) layers of neural retina. The importance of Pax 6 expression in the surface and neural ectoderm has been highlighted by experiments in the mouse. Grindley and coworkers have demonstrated that Pax 6 is essential for the formation of lens placodes from surface ectoderm. In early development Pax 6 expression occurs over the entire head surface ectoderm; this is rapidly downregulated but expression is specifically maintained in the developing lens placode.

Pax $6 \mathrm{mRNA}$ is also found in other tissues with lens forming ability - for example, the prospective pineal gland. It is likely that in these tissues other genes are switched on to override Pax 6 and divert development down a different path. The importance of Pax 6 expression in the neuroectoderm is confirmed by the abnormally broad and misshapen optic vesicles seen in Sey homozygotes. The expression of Pax 6 in the surface ectoderm, however, 
appears to be independent of and is not essential for optic vesicle formation. ${ }^{34}$ Normal Pax 6 function is required for the maintenance of its own transcription and in quails Pax 6 has been shown to bind to its own promoter. ${ }^{36}$

In 1995 Gehring's group in Switzerland showed that the eyeless gene is the fruit fly homologue of the mouse Pax 6 and that when this gene is turned on in parts of flies where it would not normally be active the flies grew extra eyes. Eyes could be induced to form on the ends of limbs, wings, and antennae. ${ }^{37}$ This work not only confirmed that Pax 6 was a master controlling gene in terms of eye development, but showed its ability to induce tissue differentiation. What was perhaps even more surprising was the fact that ectopic eyes were also seen when the mouse Small eye gene was introduced into the fruit fly. The mouse gene was able to induce development of the evolutionarily quite different compound eye of the fruit fly. It will be exciting to follow the discovery of target genes that are activated by eyeless as these may help to identify similar genes in the mouse and human.

The expression of $P A X$ genes is confined to cells that are not terminally differentiated, so candidate target genes for $P A X$ transcriptional control are repressible genes that contribute to the undifferentiated state and inducible genes that contribute to the differentiated state, such as growth factors, cell cycle regulators, receptors, and other signal transduction components. The transforming capacity of the Pax proteins and the implication of $P A X 3$ in the formation of the paediatric tumour alveolar rhabdomyosarcoma corroborate this notion. ${ }^{38}$

It is now known that DNA sequences recognised by the homeodomain are seven to eight nucleotides in length and contain the core nucleotide sequence, TAAT, flanked by three to four additional bases. Mutations in the most conserved amino acids of the third helix prevent DNA binding. ${ }^{39}$

\section{$P A X 6$ interactions}

Recent studies suggest that another member of the $P A X$ gene family, $P A X 2$, has an important role to play in ocular development. $P A X 2$ is expressed in cells that give rise to the optic stalks and in retinal cells around the choroidal fissure. The function of $P A X 2$ is not known but mutations in the gene can cause optic nerve colobomas in humans. ${ }^{40}$

Midline signalling molecules in the developing brain may be important in orchestrating the fate of specific cells. These signalling proteins are similar in many species and are related to the hedgehog gene family in Drosophila, members of which have been given various amusing names such as sonic hedgehog and tiggy-winkle hedgehog! ${ }^{41}$

It has been demonstrated that midline signalling is severely disturbed in the zebrafish cyclops mutant embryos, resulting in fusion of the eyes. $\operatorname{Pax} 2$ protein is almost completely absent and $P A X 6$ is ectopically expressed in a bridge of tissue lying in a position normally occupied by cells that form the optic stalks. This switches the fate of these cells from optic stalk to retina. From these observations it has been suggested that there is normally a midline signal (possibly sonic hedgehog) that promotes $P A X 2$ and inhibits $P A X 6$ expression in cells destined to form the optic stalks. To test this hypothesis an experiment was set up where sonic hedgehog was overexpressed in developing brain. The resultant embryos were shown to have increased $P A X 2$ and decreased $P A X \quad 6$ expression as expected and developed hypertrophied optic stalk-like structures. $^{42}$ It has been shown that $\operatorname{Pax} 6$ and $\operatorname{Pax} 2$ proteins can bind to similar DNA sequences raising the possibility that they compete for the same target sequences. ${ }^{43}$ There still remain many unexplained gaps in the hierarchy of what controls $P A X 6$ expression in humans and indeed the targets of $P A X 6$ itself.

\section{Clinical relevance}

Being able to identify the mutation causing aniridia in a particular individual or family has real advantages. It enables accurate genetic counselling and the possibility of prenatal diagnosis. It allows identification of those at risk of developing Wilms' tumour and prevents unnecessary monitoring of those not at risk.

Recent work has shown that the phenotypic abnormalities of Sey can be corrected by implanting yeast artificial chromosomes containing human $P A X 6$ gene copies into mouse embryos. ${ }^{44}$ It appears that by implanting too many copies of $P A X 6$ different eye abnormalities occur suggesting that levels of gene expression must be tightly regulated in normal eye development. Although this research is in its infancy it will surely pave the way for corrective gene therapy in affected human fetuses.

\section{The genetics of anterior segment dysgenesis}

There have been three reports of individuals with anterior segment dysgenesis who were shown to have small deletions in the short arm of chromosome 11 by cytogenetic analysis, but only one report gives details of PAX 6 mutation analysis. ${ }^{1345} 46$ Hanson et al described a family with dominantly inherited anterior segment abnormalities including Peters' and Rieger's anomalies who were found to have a missense mutation (resulting in one amino acid change) in the region of the $P A X 6$ paired box. This, they speculated, would affect DNA binding of the paired box. In the same publication a child with sporadic Peters' anomaly was reported with an interstitial deletion of the short arm of chromosome 11 encompassing the WAGR locus. This individual also had iris hypoplasia and mild developmental delay but did not have typical aniridia or the WAGR syndrome.

Two sisters have been described with Peters' anomaly and arhinia. Although no genetic analysis was performed on these individuals the clinical features fit with the expression pattern of $P A X 6{ }^{17}$

Interestingly careful re-examination of a range of Sey mice (with a $\operatorname{Pax} 6$ nonsense mutation) has revealed that there are not only features similar to aniridia but also corneal opacifications, keratolenticular adhesions, and anterior synechiae reminiscent of Peters' anomaly. ${ }^{45}$ These early lines of evidence suggest that Peters' and possibly Rieger's anomaly may also result from loss of function of one copy of $P A X 6$.

If Rieger's anomaly is found to map to $P A X 6$ then one might have reasonably expected Rieger's syndrome to follow suit. Rieger's syndrome has been extensively studied in Iowa by Murray et al. Using linkage studies and mapping techniques his group have shown that the gene for Rieger's syndrome lies on the long arm of chromosome 4 (4q25 region). ${ }^{47}{ }^{48}$ The Rieger's syndrome gene has been shown to contain a homeobox region (unpublished data from J Murray). The same region of chromosome 4 contains a gene known to cause teeth abnormalities. One can speculate that Rieger's syndrome could be caused by deletions in contiguous genes similar to that seen on chromosome 11 in the WAGR syndrome. Significant linkage to the 4q25 locus has also recently been described in a pedigree of 15 affected individuals with autosomal dominant iris hypoplasia. ${ }^{49}$ Many of the features of this condition overlap with aniridia and whether it is a variant or a truly separate entity remains open to speculation.

The genetics of anterior segment dysgenesis is thus still largely in its infancy although work is currently under way in this area particularly to determine the role of $P A X 6$ in 
Peters' anomaly. It will be interesting to learn whether mutations in $P A X 6$ are directly implicated in this spectrum of conditions that appear in embryological terms to be closely related to aniridia.

Further characterisation of alternative loci found to be mutated in these conditions may lead to the cloning of other genes involved in normal eye development. If these genes are shown to interact with $P A X 6$ one might speculate that the phenotype may depend on a particular gene product (protein) falling below a critical level at a precise stage of ocular development. Although it is tempting to concentrate solely on genetic abnormalities when trying to explain the different resultant phenotypes, one should not underestimate the importance of environmental and stochastic factors.

Funding provided by the Wellcome Trust, RED Trust, and BMA to research the genetics of anterior segment dysgenesis (AC), and from the MRC and the Northern Regional Health Authority to research the genetics of juvenile onse glaucoma (AB)

AMANDA CHURCHILL ADAM BOOTH

Molecular Medicine Unit and Ophthalomology Department, University of Leeds, Clinical Sciences Building,

St James's University Hospital, Leeds LS9 7TF

1 Bahn CF, Falls HF, Varley GA, Meyer RF, Edelhouse HF, Bourne WM. Classification of corneal endothelial disorders based on neural crest origin. Ophthalmology 1984;91:558-63.

2 Waring GO III, Rodrigues MM, Laibson PR. Anterior chamber cleavage syndrome. A stepladder classification. Surv Ophthalmol 1975;20:3-27.

3 Townsend WM, Font RL, Zimmerman LE. Congenital corneal leukomas: II. Histopathologic findings in 19 eyes with central defect in Descemet's membrane. Am $\mathcal{f}$ Ophthalmol 1974;77:192-206.

4 Waring GO III, Rodrigues MM, Laibson PR. Corneal dystrophies: I Dystrophies of the epithelium, Bowman's layer and stroma. Surv OphthalDystrophies of the ep
mol 1978;23:71-122.

5 Friedman AH, Weingeist S, Brackup A, Marinoff G. Sclerocornea and defective mesodermal migration. Br $₹$ Ophthalmol 1975;59:683-7.

6 Salmon JF, Wallis CE, Murray AD. Variable expressivity of autosomal dominant microcornea with cataract. Arch Ophthalmol 1988;106:505-10.

7 Hittner HM, Kretzer FL, Antoszyk JH, Ferrell RE, Mehta RS. Variable expressivity of autosomal dominant anterior segment mesenchymal dysgenesis in six generations. Am $\mathcal{F}$ Ophthalmol 1982;93:57-70

8 Tulloh CG. Hereditary posterior polar cataract with report of a pedigree. $\mathrm{Br}$ f Ophthalmol 1955;39:374-9.

9 Howard RO, Abrahams IW. Sclerocornea. Am f Ophthalmol 1971;71: 1254-8.

10 Nevin NC, Lim JHK. Syndrome of partial aniridia, cerebellar ataxia and mental retardation-Gillespie syndrome. Am f Med Genet 1990;35:468-9.

11 Matsuo T, Osumi-Yamashita N, Noji S, Ohuchi H, Koyama E, Myokai F, et al. A mutation in the Pax-6 gene in rat Small eye is associated with impaired migration of midbrain crest cells. Nature Genet 1993;3:299-304.

12 Ton CCT, Hirvonen H, Miwa H, Weil MM, Monaghan P, Jordan T, et al. Positional cloning and characterisation of a paired box- and homeoboxcositional cloning and characterisation of a paired box- and hom

13 Jotterand V, Boisjoly HM, Harnois C, Bigonesse P, Laframboise R, Gagne $\mathrm{R}$, et al. $11 \mathrm{p} 13$ Deletion, Wilms' tumour, and aniridia: unusual genetic, non-ocular and

14 Simola KOJ, Knuutila S, Kaitila I, Pirkola A, Pohja P. Familial aniridia and translocation $\mathrm{t}(4 ; 11)(\mathrm{q} 22 ; \mathrm{p} 13)$ without Wilms' tumour. Hum Genet 1983;63:158-61.

15 Hogan BLM, Horsburgh G, Cohen J, Hetherington CM, Fisher G, Lyon MF. Small eye (Sey): a homozygous lethal mutation on chromosome 2 which affects the differentiation of both lens and nasal placodes in the mouse. F Embryol Exp Morphol 1986;97:95-110.

16 Davisson MT. Mouse news letter 1986;75:30-31

17 Glaser T, Lane J, Houseman D. A mouse model of the aniridia-Wilms' tumour deletion syndrome. Science 1990;250:823-7.

18 Van der Meer-de Jong R, Dickinson ME, Woychik RP, Stubbs L, Hetherington C, Hogan BL. Location of the gene involving the Small eye mutation on mouse chromosome 2 suggests homology with human aniridia 2 (AN2). Genomics 1990;7:270-5.

19 Walther C, Guenet J-L, Simon D, Deutsch U, Jostes B, Goulding M, et al. Pax: a murine multigene family of paired box-containing genes. Genomics 1991;11:424-34.
20 Gruss P, Walther C. Pax in development. Cell 1992;69:719-22.

21 Stapleton P, Weith A, Urbanek P, Kozmik Z, Busslinger M. Chromosome localisation of seven Pax genes and cloning of a novel family member, Pax-9. Nature Genet 1993;3: 92-8.

22 Beebe D. Homeobox genes and vertebrate eye development. Invest OphthalmolVis Sci 1994;35:2897-900.

23 Treisman J, Harris E, Desplan C. The paired box contains a second DNAbinding domain in the Paired homeo domain protein. Genes Dev 1991;5:594-604.

24 Treisman J, Gonczy P, Vashishita M, Harris E, Desplan C. A single amino acid can determine the DNA binding specificity of homeodomain proteins. Cell 1989;59:553-62.

25 Mermod N, O'Neill E, Kelly T, Tijan R. The proline-rich transcriptional activator of CTF/NF-1 is distinct from the replication and DNA binding domain. Cell 1989;58:741-53.

26 Tanaka M, Herr W. Differential transcriptional activation by Oct-1 and Oct-2: Interdependent activation domains induce Oct-2 phosphorylation. Cell 1990;60:375-86.

27 Glaser T, Walton DS, Maas RL. Genomic structure, evolutionary conservation and aniridia mutations in the human PAX 6 gene. Nature Genet 1992 2:232-9.

28 Walther C, Gruss P. Pax-6, a murine paired box gene, is expressed in the developing CNS. Development 1991;113:1435-49.

29 Jordan T, Hanson I, Zaletayer D, Hodgson S, Prosser J, Seawright A, et al. The human PAX 6 gene is mutated in two patients with aniridia. Nature Genet 1992;1:328-32.

30 Hodgson SV, Saunders KE. A probable case of the homozygous condition of the aniridia gene. $f$ Med Genet 1980;6:478-80.

31 Fisher E, Scrambler P. Human haploinsufficiency-one for sorrow, two for joy. Nature Genet 1994;7:5-7.

32 Fantes J, Redeker B, Breen M, Boyle S, Brown J, Fletcher J, et al. Aniridiaassociated cytogenetic rearrangements suggest that a position effect may associated cytogenetic rearrangements suggest that a positio

33 Glaser T. Absence of PAX 6 mutations in Gillespie syndrome (partial aniridia, cerebellar ataxia and mental retardation). Genomics 1994;19:145-8.

34 Grindley JC, Davidson DR, Hill RE. The role of Pax-6 in eye and nasal Grindley JC, Davidson DR, Hill RE. The role

35 Abitbol M, Gerard M, Delezoide A, Sahlv I, Ribeaudeau F, Mallet I, et al. $P A X 6$ gene expression during human embryonic development at the cellular level. Am f Hum Genet 1995;57:A132,742.

36 Plaza S, Dozier C, Saule S. Quail PAX-6 (PAX-QNR) encodes a transcription factor able to bind and trans-activate its own promoter. Cell Growth Differ 1993;4:1041-50.

37 Halder G, Callaerts P, Gehring W. Induction of ectopic eyes by targeted expression of the eyeless gene in Drosophila. Science 1995;267:1788-92.

38 Barr FG, Galili N, Holick J, Biegel J, Rovera G, Emanuel B. Rearrangement of the $P A X 3$ paired box gene in the paediatric solid tumour alveolar rhabdomyosarcoma. Nature Genet 1993;3:113-7.

39 Catron CM, Iler N, Abate C. Nucleotides flanking a conserved TAAT core dictate the DNA binding specificity of three murine homeodomain dictate the DNA binding specificity
proteins. Mol Cell Biol 1993;13:2354-65.

40 Sanyanusin P, Schimmenti C, McNoe L, Ward T, Pierpont M, Sullivan M, et al. Mutation of the $P A X 2$ gene in a family with optic nerve colobomas, et al. Mutation of the $P A X 2$ gene in a family with optic nerve colobomas,

41 Ekker SC, Ungar A, Greenstein P, von Kessler D, Porter J, Moon R, et al. Patterning activities of vertebrate hedgehog proteins in the developing eye and brain. Current Biology 1995;5:944-55

42 Macdonald R, Barth K, Xu Q, Holder N, Mikkola I, Wilson S. Midline sig nalling is required for $P A X$ gene regulation and patterning of the eyes. Development 1995;121:3267-78.

43 Epstein JA, Glaser T, Cai J, Jepeal L, Walton D, Maas R. Two independen and interactive DNA-binding subdomains of the $\operatorname{Pax} 6$ paired domain are regulated by alternative splicing. Genes Dev 1994;8:2022-34.

44 van Heyningen V, Schledl A, Danes S, Fantes J, Hanson I, Tifft C, et al. YAC-transgenic correction of mutant Small eye phenotype used to explore aniridia-associated position effect and gene dosage of the PAX 6 gene. Am f Hum Genet 1995;57:A52,267.

45 Hanson IM, Fletcher J, Jordan T, Brown A, Taylor D, Adams R, et al. Mutations at the $P A X 6$ locus are found in heterogeneous anterior segment maltormations including Peters' anomaly. Nature Genetics 1994;6:168-73.

46 Beauchamp GR. Anterior segment dysgenesis keratolenticular adhesion and aniridia. $\mathcal{F}$ Pediatr Ophthalmol Strabismus 1978;17:55-8.

47 Murray JC, Bennett S, Kwitek A, Small K, Schinzel A, Alward W, et al. Linkage of Rieger syndrome to the region of the epidermal growth factor gene on chromosome 4. Nature Gemet 1992;2:46-9.

48 Datson NA, van Straalduinen A, Semina E, Meershoek E, Heus J, Hofker $M$, et al. Mapping translocation breakpoints in Rieger syndrome within a 200kb region. Am $\mathcal{F}$ Hum Genet 1995;57:A258,1496.

49 Heon E, Sheth P, Kalenak J, Sunden S, Streb L, Taylor C, et al. Linkage of autosomal dominant iris hypoplasia to the Rieger syndrome locus (4q25). Am F Hum Genet 1995;57:A193,1108.

50 Reese AB, Ellsworth RM. The anterior cleavage syndrome. Arch Ophthalmol 1966;75:307-18

51 Martha AD, Ferrell R, Mintz-Hittner H, Lyons L, Saunders G. Paired box mutations in familial and sporadic aniridia predicts truncated aniridia proteins. Am $\mathcal{F}$ Hum Genet 1994;54:801-11.

52 Hanson IM, Seawright A, Hardman K, Hodgson S, Zaletayer D, Fekete G, et al. PAX 6 mutations in aniridia. Hum Mol Genet 1993;2:915-7.

53 Martha AD, Ferrell RE, Saunders GF. Nonsense mutation in the homeobox region of the aniridia gene. Human Mutation 1994;3:297-300. 